ISSN: 2162-3104 Print/ ISSN: 2166-3750 Online

Volume 8, Issue 1 (2018), pp. 175-193

(C) Journal of International Students

http://jistudents.org/

doi: 10.5281/zenodo. 1134285

\title{
Exploring International Students' Food Choices Using Photovoice Techniques
}

\author{
Nova Corcoran \\ University of South Wales, United Kingdom
}

\begin{abstract}
This study aimed to explore international student food choices in a semirural setting using participatory photovoice techniques. Eighteen international students took photographs over 7-10 days of a typical food week and then attended a workshop where they completed three photography display and captioning tasks. Ten themes emerged linked to the food choices made by international students. These themes were aligned to a social determinants of health model and findings are discussed in the context of improving international students' food experiences through focusing on individual lifestyles, social networks and living and learning environments.
\end{abstract}

Keywords: food choices, international students, photovoice, university

The United Kingdom is a popular destination choice for international students. In 2015-2016 there were approximately 430,000 international students coming to study in the United Kingdom (UK Council for International Student Affairs, 2017). International students are an asset to the United Kingdom and the universities that host them. They help to sustain the UKs research base, allow investment in new university facilities and generate global connections alongside helping to sustain jobs in local economies (UKCISA, 2014). The economic dependence of universities on international students makes it important to gain an understanding of the experiences faced by international students studying in the United Kingdom (Brown et al., 2010). 
Economic dependence is not the only reason international students are important. A university is not just a teaching and learning facility. A university provides life education for young adults (Herdlein \& Zurner, 2015) and is a "school of knowledge of every kind" (Newman, 1852). International students have a strong contribution to the development of different forms of learning as they enhance cross-cultural understanding and bring new ideas and experiences into the classroom, benefitting the whole university community. As Hegarty (2014) aptly surmises, international students contribute to the "personality" of the university and the experiences that a university can offer to students.

University support is important for international student success in a host county and a positive learning experience reduces the stressors that students may experience when studying in the United Kingdom (Lillyman \& Bennett, 2014). Most universities recognize the importance of supportive academic services for international students, but less attention is directed to educational, social and cultural adjustment (Cho \& Yu, 2015). Research suggests that international students experience difficulties in adjusting to the environment of a home country (Smith \& Khawaja, 2011; Hyams-Ssekasi et al., 2014). A focus on these areas can support student adjustment to daily living and promote a better learning experience.

A university is an ideally placed setting to promote health and wellbeing in international students. It can offer opportunities to actively promote international student health, and influence health outcomes in students. Doherty et al. (2011) highlights the potential role that universities can play in promoting a healthier approach to food, and make reference to the particular "foodscape" of a university which either facilitates or restricts healthy eating choices. Adjustment to food may be an important difficulty that international students face (Hartwell et al., 2011) and a university has huge potential to promote positive cultural and social adjustment in this area. With this in mind, this study aimed to explore international student food choices in the United Kingdom and to identify the influences from the wider environment and the university environment on these choices.

\section{International Students Food Choices}

Research with international students and food choices has received limited attention in the United Kingdom, and most research comes from the United States, or from studies with non-student communities. Research with immigrant populations documents a deterioration in immigrants' health status when they move to a new country and dietary changes play a role in 
this deterioration (Sanou et al., 2014). Student studies have shown similar trends to immigrant studies and link studying overseas with health risks such as weight gain (Leu \& Banwell, 2016; Almohanna et al., 2015). The acculturation process that students experience may mean a transition in diet and the adoption of Western diet patterns (Sukalakamala \& Brittin, 2006) which exposes students to health risks.

Food is an integral part of the environment and culture of a host country. A social ecological approach to health suggests that there are multiple determinants that influence health including individual, close networks, community, and societal influences (Kowitt et al., 2015). If we consider food in the same way as health, it is clear that there will be multiple factors influencing students' food choices. Studies with university student populations illustrate a wide range of determinants on eating behaviors including individual factors, social environment, physical environment, macro environment and university characteristics (Deliens et al., 2014). At a broad level the social and physical environment of the university contributes to eating behaviors (Lacaille et al., 2011), and at an individual level financial instability, lack of culinary knowledge and time restrict the ability to prepare and eat healthy foods (Murray et al., 2016). Research with international students in the United States also highlights multiple influences on diet including the food environment, campus environment, individual preferences, time and religion (Alakaam et al., 2015). International students, like home students, may be influenced by a wide range of determinants in their food choices whilst simultaneously managing the transition to culturally different food environments.

Choices that international students make about food are likely to be complex and for food related health promotion efforts to be effective a clear understanding of the factors that influence food choice is needed. This means using techniques that aid our understanding of the cultural contexts in which people make food related choices. The Dahlgren and Whitehead social determinants of health model (Dahlgren \& Whitehead, 1991) is widely used in public health in the United Kingdom to highlight the broad spectrum of influences on health and reflects the social ecological approach to health. This model is presented as a rainbow with the individual centered in the middle. Surrounding the individual are four layers; individual lifestyle factors, social and community networks, living and working conditions and general socioeconomic, cultural and environmental conditions. For example, the university environment or local community influences are represented in the outer layers of the model with individual lifestyle factors, such as personal choices or friends, represented in the inner layers. 


\section{Photovoice Research}

In health, photography has proved to be a suitable tool to explore lived experiences (Murray \& Nash, 2016). Photovoice has been developed to use photography in a way that gives a voice to photographs, predominately as a catalyst for social change. It is a tool that gives people the opportunity to photograph their everyday life providing a basis for critical discussion around personal and community issues (Wang et al., 2004). This study wanted to explore the living experiences of international students and adapted photovoice techniques to explore food choices. It was hoped that this technique would encourage participation in international students in defining important food related issues and contribute to new knowledge in the context of everyday university life.

Although photovoice has not been specifically used to look at international student's food choices it has been used separately in both student and food related research. Photovoice has been used for student advocacy projects (Goodhart et al., 2006), and to examine international students' academic and cultural adjustment (Wang \& Hannes 2014). In addition, this technique has been able to show physical and environmental challenges in consuming a healthy diet in ethnic minority groups (Heidelberger \& Smith 2015), and to explore factors that make healthy food choices easier (Watts et al., 2015). It has also been used to identify and explore food environments in communities by citizens living in those areas (Heart Healthy Hoods 2016). Using existing photovoice studies for inspiration, for example work by Ardery et al. (2016) in pneumonia prevention, it was decided that photovoice techniques could be aligned to a social determinants of health model to capture international student experiences of food in a participatory way alongside highlighting the determinants of food choices within and around the university.

\section{RESEARCH METHOD}

\section{Study Aim}

This study aimed to explore international student experiences of food in the United Kingdom using participatory photovoice methods. After data was collected the study aimed to align findings to the Dahlgren and Whitehead (1991) social determinants of health model. It was assumed that this would assist in the identification of influential determinants of food choices and highlight possible health and well-being opportunities. 


\section{Participants}

Eighteen full time postgraduate international students (known as participants in this study) who had resided in the United Kingdom for 6 months or more from seven different African and Asian countries (Nigeria, Libya, Ghana, Somalia, the Philippines, Pakistan and India) were recruited to the project. They were predominately Nigerian students (11/18) aged between 22 and 41 years old, split between 11 females and seven males. Recruitment was via direct course advertising and using a snowballing technique. Participants were given guidance to photograph what they eat, where they buy food, and the places they eat or prepare food. They were asked to take photographs over 7-10 days and to aim for 24-36 photographs that capture their typical food week. All students expressed the preference of using their mobile phone cameras to complete the task.

\section{Methodology and Tasks}

After the photographs had been taken, collected and printed the participants attended one of two identical one day photovoice workshops. The workshops were centered on a range of tasks and activities. Participants were given their printed photographs to label and/or sort before the tasks began. Various craft materials were provided for participants and included a wide range of colored paper, pens, glue and scissors to help them display photographs. For each task participants were asked to caption and display photographs in any way they wished using the SHOWeD technique. This is based on Freire's educational questioning strategy (Wallerstein \& Bernstein 1998; Wang et al. 1998). The SHOWeD technique is a series of questions which encourages participants to identify the problem or asset and reflect on its importance. The questions participants are asked were: What do you See here? What is really Happening? How does this relate to Our lives? Why does this problem or strength exist? What can we Do about it?

Task 1: Pin-interest. Participants were asked to choose their favorite food photograph and caption this. Task 2: Storytelling. Participants were asked to select between one and eight photographs to represent a typical food day. Task 3: Storytelling. Participants were asked to select between one and four photographs in response to the question: "What would you show a friend or family member who had not visited the United Kingdom about your food in the United Kingdom?" The workshops were documented through photographs using the social media application Instagram. 


\section{RESULTS}

A theme analysis was undertaken after the workshops were completed. Photographs and captions were viewed multiple times to identify key themes for each task. Themes were generated by looking for similarities or repetition of images within photographs or captions. Seven themes emerged from the three tasks. These were; the importance of traditional dishes, appearance and taste of food, university day versus a non-university day, cooking skills, diverse breakfasts, availability of traditional foods and trying new foods. Three overarching themes also emerged from all three tasks. These were cost, the locations that food is purchased and traditional meals as health choices (see Table 1). These themes were aligned to the different layers of the Dahlgren and Whitehead (1991) model using the layers of: Individual lifestyle, social networks, living and working conditions and/or general socioeconomic conditions.

Table 1. Data themes and matching social determinants.

\section{Theme}

Importance of traditional dishes

Appearance and taste of food

University day verses a non-university day

Cooking skills

Diverse breakfasts

Availability of traditional foods

Trying New foods

Theme from all areas: Costs

Theme from all areas: Location food is purchased

Theme from all areas: Traditional meals Individual lifestyle, social networks, as healthy choices
Area of Dahlgren \& Whitehead model

Individual lifestyle, social networks

Individual lifestyle

Living and working conditions

Individual lifestyle, social networks

Individual lifestyle

Living and working conditions, general socioeconomic conditions.

Individual lifestyle, social networks, Living and working conditions

Living and working conditions, general socioeconomic conditions,

Living and working conditions 


\section{Task 1: Pin-Interest}

\section{Importance of Traditional, Savory Meals}

The majority of participants (17 of 18 ) chose to display a traditional meal from their home country. Of these dishes, 16 of the 17 were selfprepared and represented a wide range of dishes. All 17 photographs showed savory dishes included noodle or rice based dishes, for example, two participants showed "Efo rice," and three showed "Indonie noodles." Others showed "soups" or stews which were thick vegetable or meat based dishes, such as "vegetable soup" which contains vegetables and diced meat or chicken gizzards. Dishes included African dishes such as "Onam" and "Eba" and Asian dishes such as "Chicken Biryani." Food captioned as "best" or "favorite" food were all traditional dishes from home-for example one participant captioned: "Spaghetti with pepper stew and garnished fish. My best meal since I got to wales" (Participant D). There were some common ingredients across the photographs with fried chicken being the main meat, and fried plantain the main vegetable. Some of the dishes were made with the same ingredients that would be used in the participant's home countries but others used the task to show how they made a traditional dish with a substitute ingredient (i.e., instant potato mash or potato croquettes instead of yam).

\section{Appearance and Taste of Food}

Captions frequently highlighted that dishes were chosen as they looked attractive or tasty, and there was some emphasis on food looking "nice,"-for example, "looks good huh?" (Participant B), and "I like this, it looks nice and reminds me of home" (Participant G). There were also numerous captions referring to taste, for example "Efo Riro, the African dish that leaves you salivating" (Participant L).

\section{Task 2: A Typical Food Day}

\section{University Day Verses a Non-University Day}

Just under half of participants (eight of 18) indicated that they had two different types of food days; a university day and a non-university day. Those that showed that they had two different days gave reasons such as having no time to cook, skipping meals or having snacks for breakfast, 
lunch or brunch on those days. One participant captioned "In the UK we change our meal time because we don't have time to cook and eat three times a day" (Participant F). This is also evident in the photographs that participants showed. For example, one participant showed a university day of cheese burger, microwave lasagna, fried chips and sausage, but a day of no classes showed home cooked spaghetti and fried chicken, plantain and kale vegetable soup and special chicken (Participant G). One participant suggested limited traditional meal options at the university are a reason for different food choices on a university day "I would love an Africa meal, instead I skip lunch or have a pre pack lasagna" (Participant E).

Half of participants (nine of 18) did not distinguish between different days of the week. Two or three meals in a typical day were shown by four participants and five participants showed they ate four or more meals a day including combinations of breakfast, brunch, lunch, snacks, tea, dinner, and supper. Despite the different types of days' participants presented, takeaway food was commonly represented and nine of 18 participants showed at least one take-away meal-that is, a burger, fried chicken, or noodles - and five others showed a meal that they had eaten in a restaurant. Notably absent from the photographs is fruit. Only five of 18 participants showed photographs of fruit consisting of bananas, oranges, grapes or watermelon. Bananas and grapes were the most common.

\section{Cooking Skills}

Cooking is something that some of the participants enjoy for example one caption said "On a day I don't have lectures I take my time to cook, I cook massive and have a special dish" (Participant G). Some participants (three of 18) photographed and captioned their newly developed cooking skills-for example, "I learnt to cook chicken wrap with spice and veggies" (Participant L). Another participant photographed a rice based dish and captioned, "I did not know I could make this meal...I made do with what was available to me" (Participant $\mathrm{C}$ ). A typical food day with take-out meals, or meals that were the same (noodles and egg for breakfast and lunch) were shown by two participants and captioned that the reason for this was that they can't cook very well (Participants $\mathrm{C}$ and $\mathrm{O}$ ).

\section{Diverse Breakfasts}

Typical food days' highlight considerable diversity in breakfast meals. Some participants (six of 18) showed a typical United Kingdom-style 
breakfast of cereal or toast/bread sometimes with tea or milkshakes. Photographs of fried English breakfasts (bacon, egg, sausages, hash-browns, baked beans and tomatoes) were shown by two of 18 participants, and two of 18 participants showed take-away breakfasts of a bacon roll and a burger. The remaining eight of 18 showed more traditional home cooked meals. 'Indomie noodles' was shown by three of 18 participants, and other participants showed dishes such as yogurt and pastries, yam porridge with vegetables, red chowdri porridge and a dish of chips, fried chicken and coleslaw. Some photographs showed a mix of traditional and Western foods for example naan bread and chocolate biscuits, chapatti, and omelet and peanut butter sandwiches with condensed tinned milk.

\section{Task 3: What would you show a friend or family member who has not visited the United Kingdom about your food in the United Kingdom?}

\section{Availability of Traditional Foods}

The ability to make traditional meals in the United Kingdom or favorite new foods was shown by 15 of 18 participants. Reasons to come to the United Kingdom were shown by eight of 18 participants through photographs, for example one photograph showed two traditional Libyan dishes with the caption, "don't worry you will not miss these yummy foods here" (Participant F). Another showed an Asian meal captioned, "you can still eat traditional food like cooked cassava and fried beef" (Participant J). Some participants showed simple traditional foods that can be bought in the United Kingdom for example a photograph of brown beans with the caption, "look, we also get brown beans here" (Participant I). One participant showed a gas cooker and captioned, "a gas cooker is used in houses in the UK the same as Nigeria" (Participant A), and one participant student showed a meal plus an Asian shop photograph with the caption, "I am in the UK and I still get to eat my best meal" (Participant $\mathrm{N}$ ).

\section{Trying New Foods}

Favorite new foods were shown by seven of 18 participants, and five of 18 participants highlighted foods that visitors to the United Kingdom have to try-for example, "you have to try the milk here, it is liquid and very creamy" (Participant G). Other foods that participants showed and captioned for visitors to the United Kingdom included doughnuts, fried 
breakfasts, jacket potatoes with baked beans, cheesecake, and barbeques: "try it, you cannot find barbeque in Karela" (Participant J).

\section{Overarching Themes}

Cost

Only two of 18 participants mentioned the cost of food in photographs, and both of these indicated that food in the United Kingdom is cheap. One participant showed a photograph of a 2-liter bottle of lemonade and captioned "fizzy drinks are cheap so you can drink as much as you like" (Participant G) another showed fried chicken, "Chicken! My favorite from Nigeria. It's one of the cheapest things you can find" (Participant C).

\section{Locations for Purchasing Food}

The photographs show that participants buy food from a wide variety of places. Given the small range of options in the local area some participants show they travel to the closest city (about $25 \mathrm{~min}$ on the train). Food was bought from a wide variety of locations including a small Asian store local to the university. Photographs of African foods bought from a man with a van who drives to the local area with African foods were shown by four of 18 participants. The two supermarkets in the local area within 30 min walking distance were also photographed or captioned by nine participants. Photographs also showed some participants have visited the local city to buy food from market stalls. Different take away options locally were also photographed including a fast food van near the university and a local Chinese take away. Restaurants from the closest city were shown by four of 18 participants. Only two of 18 participants showed food that was purchased from the university (both fried breakfasts).

\section{Traditional Meals as a Healthy Choice}

Common across the photographs was the notion that the choices of food were healthy. A wide range of vegetables were presented by all participants in photographs with popular choices of carrots, plantain, and mixed vegetables. One participant captioned the nutritional breakdown of all their meals (Participant B). Other participants made reference to five fresh fruit and vegetables a day "I stay healthy with 5 a day" (Participant L). Some participants (two of 18) captioned photographs with hashtags including 
words linked to health-for example, \#keepithealthy, \#eggs, \#onions, \#redpeppers, \#tomatos, \#corianderleaves, \#energy (Participant M). A perception of traditional food as a healthy option was also displayed by some participants; a photograph of fried plantain and fried egg sauce is captioned "balanced diet" (Participant I) and a white rice with battered fish meal as "healthy food" (Participant K).

\section{DISCUSSION AND CONCLUSIONS}

International university students continue to eat traditional foods from their home countries in the United Kingdom and substitute unavailable foods to make replica traditional dishes. They also place strong emphasis on the desire to have food that looks nice, tastes nice and frequently refer to their traditional dishes as healthy choices. Amos and Lordly (2014) also note the importance that international students place on maintaining cultural identity with traditional food, plus the equation of traditional foods with health. This suggests that the ability to cook and produce traditional foods is important for international students, alongside maintaining the belief that traditional foods are healthy foods. As all international students in this group demonstrated that they cooked for themselves, increasing knowledge on new cooking methods, that is, grilling rather than frying as a "healthier" choice would be a good starting point, as fried foods are widely eaten. In addition, increasing nutrition education on some substitute foods that are low in nutrients (e.g., instant mashed potato) and increasing knowledge of other alternatives could encourage healthier choices. Edwards et al. (2010) found that there may be some reluctance in international students to try new foods, but the current study suggests that students are experimenting with new foods, and are keen to recommend new foods to others. This demonstrates a degree of cultural adjustment and suggests students are keen to show others how they have adjusted to live in the United Kingdom.

Traditional meals that were presented in this project usually included a wide range of vegetables and this practice should continue to be promoted. Preparing meals may be associated with the desire to save money, as well as familiarities with cooking techniques (Jones et al., 2014), and it was noted that many students prepared traditional foods that required competent cooking skills. There may be a relationship between competent cooking skills and healthier meal choices, for example research indicates that cooking skills correlate positively with weekly vegetable consumption (Hartman et al., 2013). This is an area that would warrant future investigation as the cooking skills of these students may not represent the 
cooking skills of all international students, particularly as these students are all postgraduate students and may be older on average than undergraduate students.

Nearly half of participant's skip meals or change their eating patterns on a university day and this seems to be attributed to the inability to cook lunch. Research with other U.K. international students has also found skipping meals is common (O'Sullivan and Amirabdollahian, 2016). Time has been highlighted by participants as a reason for not cooking traditional meals. Other research supports this finding and Hartwell et al. (2011) suggests time may be a reason why meal times are modified. A small number of participants say they have no time for breakfast. Pan et al. (1999) found that in a study in the United States with Asian students that reasons for missing breakfast, and the decrease of meal frequency was partly due to class times. This is supported by other work with international students (Edwards et al., 2010) and with immigrant populations (Wandel et al., 2008). Interestingly a high number of participants did show breakfast meals illustrating in this study that it may not be the meal that is the commonly missed.

There is some dissatisfaction expressed by the lack of traditional food choices on campus, and this echoes findings in a recent study in the United States which found international students were generally unsatisfied with food on campus (Yan \& Fitzpatrick, 2006). The students who show 4 or 5 meals a day often include snacks and this may be because main meals have been skipped. Kremmyda et al. (2008) note that in Greek students in the United Kingdom that there is an increase in snack foods and a decrease in other foods such as fresh fruit or vegetables, but without a comparison to what these students ate before coming to the United Kingdom it would be difficult to suggest this is the case in this study. In this study students demonstrate the desire to cook and eat traditional foods and provision of university facilities that allow re-heating of foods may encourage students to bring pre-prepared lunches to campus and reduce meal skipping or snacking.

Consumption of fruit was generally low in most participants in this study, and generally not photographed by participants. A study of international students in Ghana noted that African students were more likely that white students to say fruits were not important (Danquah et al., 2010) and this could be in part due to both cost, availability or seasonality of fruit as these are major barriers to fruit and vegetable consumption (Hartman et al., 2013). However, as cost was rarely mentioned as a barrier to food choices it is possible that lack of experience in eating different fruits is a factor for non-consumption. Promoting fruit by better product placement 
and health information has been found to increase fruit consumption on campus (Cardenas et al., 2015). As some participants skip lunch or snack at the university, university food provision could include affordable fruit (i.e. bananas and grapes were the most common fruits shown) which may increase fruit consumption, or promote alternative seasonal fruit using free 'tasters' to encourage the trying of new fruit, for example kiwi fruit or pears.

Take away meals are displayed by a number of participants in photographs especially fried chicken and burgers. A study in U.S. college students found that perceptions of fast food restaurants as cheap and timesaving were reasons for using fast food restaurants (Morse \& Driskell et al., 2009). Reducing take away consumption means addressing multiple issues including time constraints and the need to replicate meals that look nice. As this group demonstrate fairly competent cooking skills potential intervention ideas include provision of quick, healthy recipes based on traditional foods or designed by students (See the University of New South Wales (2016) for an example). Holt et al. (2015) suggested providing information on preparing food quickly and cheaply. Alternatively promoting bulk cooking or shared meals may also be an option. For example, research with dinner group participants in Australia (i.e., roommates) found that social interaction and confidence in cooking increases (Ball \& Brown, 2012) and this may be a good way of encouraging social support, healthy food options and money saving in international students. Finally, pressure could be exerted on food providers locally (on and off campus) to provide reasonably priced healthier alternatives to take away meals or to consider serving more international snacks on campus for example fried plantain, noodles and boiled eggs were all commonly eaten by participants.

Many participants chose to show photographs of foods as a way of attracting people to the United Kingdom. Possibly these photographs and captions reflect their own anxieties before they came to the United Kingdom about food. Lillyman and Bennett (2014) suggest practical information related to food prior to coming to the United Kingdom and in the first few weeks could help international students. This could be investigated further in future research as there are numerous ways this information could help prepare students. For example, new international student information could highlight culturally diverse foods available or local food stores. This could be given on websites or in course information, perhaps with pictures showing traditional meals that can be made in the United Kingdom such as ones showed by participants in this project.

Finally, the sample size in this study was relatively small as the photo voice technique does not lend itself well to large population groups. A 
different methodology i.e. focus groups may have elicited different findings, but may not have captured the visual component of food, and allowed participants freedom to choose what was important to them about food. The sample also represents seven different counties, predominately Nigeria, and international students from different countries may present different findings. These students were also postgraduate students and demonstrated clear cooking competence. This may be different to undergraduate students and this may have influenced food choices or the photographs presented. This study used students who had been in the United Kingdom for 6 months or more to capture the routine choices that they make about food. Findings might be different for students who have recently arrived in the United Kingdom. Finally, access to food and food choices in a semi-rural area may be different to a city-based university where is it assumed more diverse food choices are available.

\section{IMPLICATIONS}

This study found that using photovoice techniques with international students can capture international student experiences of food alongside highlighting the determinants of food choices within and around the university. The results presented from the photovoice tasks offers direction for areas to explore in the future to promote cultural and social adaptation to the United Kingdom alongside promoting healthy eating in international student groups. The findings from this study suggest that if we wanted to promote healthy food choices with international students in the United Kingdom then action is needed at different layers of the Dahlgren \& Whitehead model (1991). This study found that by aligning the photovoice themes to a social determinants model of health then influences on food choice could be identified from different layers of the model. Individual lifestyles of students, which include appearance of foods and cooking skills clearly influence much of their daily eating routines and habits. Living and working conditions, that is, the university environment and structure of the university day also clearly have an influence on food choices and food consumption patterns, where many students considered a day at university to be an unhealthy food day. In addition, social economic conditions such as local availability of foods clearly impacts on the decisions to substitute foods instead of using traditional ingredients.

For international students, health promotion efforts should focus on nutrition education that increases healthy options for substitute foods, promotes alternative cooking methods, that is, grilling instead of frying and 
increases knowledge of low cost or seasonal fruit that is available in the United Kingdom. International student cooking competencies were particularly high in this group and therefore the promotion of shared meals or dining clubs may also be an area for future investigation with international student groups as this may promote both food diversity, and promote social and cultural exchange experiences contributing to international student wellbeing.

Universities need to be more widely involved in promoting health of international students. A suggestion from this study is that universities consider the provision of cheap, healthy alternatives to take away foods and snacks in the university setting, alongside consideration of offering simple traditional snack foods that are attractive to students. In addition, allowing access to facilities that enable the re-heating of foods may encourage students to bring pre prepared meals, and reduce unhealthy snacking on campus. Promotion of seasonally available fruit, and tasting sessions may encourage fruit consumption on campus. Finally highlighting food stores that sell culturally diverse food options, or commonly substituted foods may help students adjust to life in the United Kingdom before they come to the United Kingdom, and when they first arrive.

\section{REFERENCES}

Alakaam, A. A., Castellanos, D. C., Bodzio, J., \& Harrison, L. (2015). The factors that influence dietary habits among international students in the United States. Journal of International Students, 5(2), 104-120.

Almohanna, A., Conforti, F., Eiger, W., \& Barbeau, W. (2015). Impact of dietary acculturation on the food habits, weight, blood pressure and fasting blood glucose levels of international college students. Journal of American College Health, 63(5), 307-314.

Amos, S., \& Lordly, D. (2014). Picture this: A photovoice study of international students' food experience in Canada. Canadian Journal of Dietary Practice and Research, 75(2), 59-63.

Ardrey, J., Desmond, N., Tolhurst, R., \& Mortimer, K. (2016). The Cooking and Pneumonia Study (CAPS) in Malawi: A nested pilot of photovoice participatory research methodology. PLoS One, 11(6), e0156500.

Ball, B., \& Brown, L.B. (2012). Qualitative description of college students' dinner groups. Journal of Nutrition, Education and Behaviour, 44(1), 29-35.

Brown, L., Edwards, J., \& Hartwell, H. (2010). A taste of the unfamiliar. Understanding the meaning attached to food by international postgraduate students in England. Appetite, 54(1) 202-207. 
Cardenas, M. K., Benziger, C. P., Pillay, T. D., \& Miranda, J. J. (2015). The effect of changes in visibility and price on fruit purchasing at a university cafeteria in Lima, Peru. Public Health Nutrition, 18(5), 2742-2749.

Cho, J., \& Yu, H. (2015). Roles of university support for international students in the United States: Analysis of a systematic model of university identification, university support and psychosocial well-being. Journal of Studies in International Education, 19(1), 11-27.

Danquah, A. O., Odjoji, Y., Graham-Acquaah, S., \& Steiner-Asiedu, M. (2010). A pilot study of the dietary and physical activity behaviors of international students: implications for health promotion. African Journal of Food Science, 4(3), 86-92.

Dahlgren, G., \& Whitehead, M. (1991). Policies and strategies to promote social equity in health. Stockholm, Sweden: Institute for Futures Studies.

Deliens, T., Clarys, P., De Bourdeaudhuij, I., \& Deforche, B. (2014). Determinants of eating behavior in university students: A qualitative study using focus group discussions. BMC Public Health, 14, 53.

Doherty, S., Cawood, J., \& Dooris, M. (2011). Applying the whole-system settings approach to food within universities. Perspectives in Public Health, 131(5), 217-224.

Edwards, J. S. A., Hartwell, H. L., \& Brown, L. (2010). Changes in food neophobia and dietary habits of international students. Journal of Human Nutrition and Diet, 23(3), 301-311.

Goodhart, F. W., Hsu, J., Baek, J. H., Coleman, A. L., Maresca, F. M., \& Miller, M. B. (2006). A view through a different lens: photovoice as a tool for student advocacy. Journal of American College Health, 55(1), 53-56.

Hartman, H., Wadsworth, D. P., Penny, S., van Assema, P., \& Page, R. (2013). Psychosocial determinants of fruit and vegetable consumption among students in a New Zealand university. Results of focus group interviews. Appetite, 65, 35-42.

Hartwell, H. J., Edwards, L., \& Brown, L. (2011). Acculturation and food habits: Lessons to be learned. British Food Journal, 131(11), 1393-1405.

Heart Healthy Hoods. (2016). Photovoice Villaverde Project. Retrieved from www.hhhproject.eu

Hegarty, N. (2014). Where are we now-The presence and importance of international students to universities in the United States. Journal of International Students, 4(3), 223-235.

Heidelberger, L., \& Smith, C. (2015). The food environment through the camera lenses of 9- to 13-year-olds living in urban, low-income, midwestern households: A Photovoice Project. Journal of Nutrition, Education and Behaviour, 47(5), 437-445.

Herdlein, R., \& Xerner, E. (2015). Student satisfaction, needs and learning outcomes: A case study approach at a European University. Sage Open, 5(2). doi: $10.1177 / 2158244015580373$ 
Holt, M., Monk, R., Powell S., \& Dooris, M. (2015). Student perceptions of a healthy university. Public Health, 129(6), 674-683.

Hyams-Ssekasi, D., Mushibwe, C. P., \& Caldwell, E. F. (2014). International education in the United Kingdom: The challenges of the golden opportunity for Black-African students. Sage Open, 4(4). doi: 10.1177/ 2158244014562386

Jones, S.A., Walter, J., Soliah, L., \& Phifer, J.T. (2014) Perceived motivators to home food preparation: focus group findings. Journal of the Academy of Nutrition and Dietetics, 114(10), 1552-1556.

Kowitt, S., Woods-Jaeger, B., Lomas, J., Taggart, T., Thayer, L., Sutton, S., \& Lightfoot, A.F. (2015). Using photovoice to understand barriers and facilitators of cardiovascular health among African American Adults and adolescents, North Carolina 2011-2012. Preventing Chronic Disease, 12, 150062. Retrieved from www.cdc.gov/pcd/2015/15_0062.htm

Kremmyda, L. S., Papadaki, A., Hondros, G., Kapsokefalou, M., \& Scott, J. A. (2008). Differentiating between the effect of rapid dietary acculturation and the effect of living away from home for the first time, on the diets of Greek students studying in Glasgow. Appetite, 50, 455-463.

Lacaille, L. J., Dauner, K. N., Krambeer, R. J., \& Pedersen, J. (2011). Psychosocial and environmental determinants of eating behaviors, physical activity, and weight change among college students: A qualitative analysis. Journal of American College Health, 59(6), 531-538.

Leu, J. H., \& Banwell, C. (2016). Looking for a taste of home: A qualitative study of the health implications of the diets of Australian-based Southeast Asian students. Global Journal of Health Science, 8(3), 101-112.

Lillyman, S., \& Bennett, C. (2014). Providing a positive learning experience for international students studying at UK Universities: A literature review. Journal of Research in International Education, 13(1), 63-75.

Morse, K. L., \& Driskell, J. A. (2009). Observed sex differences in fast-food consumption and nutrition self-assessments and beliefs of college students. Nutrition Research, 29(3), 173-179.

Murray, L., \& Nash, M. (2016). The challenges of participant photography: A critical reflection on methodology and ethics in two cultural contexts. Qualitative Health Research, 27(6), 923-937.

Murray, D. W., Mahadevan, M., Gatto, K., O’Connor, K., Fissinger, A., Bailey, D., \& Cassara, E. (2016). Culinary efficacy: An exploratory study of skills, confidence, and healthy cooking competencies among university students. Perspectives in Public Health, 136(3), 143-151.

Newman, J. H. (1852). The idea of a university. Retrieved from www.newmanreader.org/works/idea/

O’Sullivan, N., \& Amirabdollahian, F. (2016). Loyal tongue, liberal mind. International student's experiences on dietary acculturation in England. Journal of International Students, 6(1), 107-127. 
Pan, Y. L., Dixon, Z., Himburg, S., \& Huffman, F. (1999). Asian students change their eating patterns after living in the United States. Journal of the American Dietetic Association, 99(1), 54-57.

Sanou, D., O’Reilly, E., Ngnie-Teta, I., Batal, M., Mondain, N., Andrew, C., . . . Bourgeault, I. L. (2014). Acculturation and nutritional health of immigrants in Canada: A scoping review. Journal of Immigrant and Minority Health, 16(1), 24-34.

Smith, R. A., \& Khawaja, N. G. (2011). A review of the acculturation experiences of international students. International Journal of Intercultural Relations, 35(6), 699-713.

Sukalakamala, S., \& Brittin, H. C. (2006). Food practices, changes, preferences, and acculturation of Thais in the United States. Journal of the American Dietetic Association, 106(1), 103-108.

UKCISA. (2014). Impact of international students. Retrieved from http://institutions.ukcisa.org.uk/Info-for-universities-colleges-schools/Policy-research--statistics/

UK Council for International Student Affairs. (2017). International student statistics: UK higher education 2015/6. Retrieved from https://institutions. ukcisa.org.uk/info-for-universities-colleges--schools/policy-research-statistics/research--statistics/international-students-in-uk-he/\#International(non-UK)-students-in-UK-HE-in-2015-16

University of New South Wales, Australia. (2016). ARC student cookbook. Retrieved from https://www.arc.unsw.edu.au/read/the-student-cookbook

Wallerstein, N., \& Bernstein, E. (1998). Empowerment education: Freire's ideas adapted to health education. Health Education Quarterly, 15(4), 379-394.

Wandel, M., Råberg, M., Kumar, B., \& Holmboe-Ottesen, G. (2008) Changes in food habits after migration among South Asians settled in Oslo: The effect of demographic, socio-economic and integration factors. Appetite, 50, 376385 .

Wang, C. C., Wu, K. Y., Zhan, W. T., Carovano, K. (1998). Photovoice as a participatory health promotion strategy. Health Promotion International, 13(1), 75-86.

Wang, C. C., Morrel-Samuels, S., Hutchingson, P. M., Bell, L., \& Pestronk, R. M. (2004). Flint photovoice: community building among youth, adults and policy makers. American Journal of Public Health, 94(6), 911-913.

Wang, Q., \& Hanes, K. (2014). Academic and socio-cultural adjustment among Asian international students in the Flemish community of Belgium: A photovoice project. International Journal of Intercultural Relations, 39, 66-81.

Watts, A. M., Lovato, C. Y., Varr, S. I., Hanning, R. M., \& Masse, L. C. (2015). Experiences of overweight/obese adolescents in navigating their home food environment. Public Health Nutrition, 18(18), 3278-3286. 
Yan, Z., \& Fitzpatrick, K. (2016) Acculturation and health behaviors among international students: a qualitative approach. Nursing and Health Sciences, 18(1), 58-63.

NOVA CORCORAN, MSc, is a senior lecturer and course leader for the MSc Public Health at the University of South Wales (United Kingdom). Nova's interests are in health promotion and health communication with minority groups. Email: nova.corcoran@southwales.ac.uk

Manuscript submitted: 20 September 2016 Manuscript revised: November 222016 Accepted for publication: March 2017 